\title{
The effect of combined TPF and intensity modulated radiotherapy after TPF induction chemotherapy on locally advanced nasopharyngeal carcinoma: a retrospective analysis
}

\author{
Lu Zheng, Quan Xu, Ziru Yang, Yanping Bei, Jingtao Tong, Shuang Ye, Jing Hu, Xue Chen, Jiaming Lv \\ Department of Radiotherapy, Lihuili Hospital, Ningbo Medical Center, Ningbo, China \\ Contributions: (I) Conception and design: L Zheng, Y Bei; (II) Administrative support: None; (III) Provision of study materials or patients: L \\ Zheng, Q Xu, Z Yang; (IV) Collection and assembly of data: S Ye, J Hu, X Chen, J Lv; (V) Data analysis and interpretation: L Zheng, J Tong; (VI) \\ Manuscript writing: All authors; (VII) Final approval of manuscript: All authors. \\ Correspondence to: Yanping Bei. Department of Radiotherapy, Lihuili Hospital, Ningbo Medical Center, 57 Xingning Road, Yinzhou District, Ningbo \\ 315000, China. Email: echobyp@163.com.
}

\begin{abstract}
Background: To evaluate the efficacy and toxicity of docetaxel, cisplatin, and fluorouracil (TPF) regimen followed by intensity modulated radiotherapy (IMRT) on locally advanced nasopharyngeal carcinoma (NPC). Methods: A total of 150 patients with locally advanced NPC [American Joint Committee on Cancer (AJCC) 2009 stage IIIa-IVb] received 2 or 3 cycles of a TPF regimen as induction chemotherapy. A group of 67 participants (TPF group) continued to receive TPF chemotherapy and radiotherapy, and the remaining 83 participants (P group) received cisplatin chemotherapy and radiotherapy.

Results: A median follow-up of 35 months (4-66 months) showed that there was no significant difference between $\mathrm{P}$ group and TPF group in progression-free survival (PFS) and overall survival (OS). The incidence rate of myelosuppression at 3-4 degrees was $16.9 \%$ and $34.3 \%$ in the $\mathrm{P}$ group and TPF group $(\mathrm{P}=0.029)$, respectively, and the oral mucosa reaction at $3-4$ degrees was $18.1 \%$ and $37.3 \%$ in the $\mathrm{P}$ group and TPF group, respectively $(\mathrm{P}=0.007)$. The $3-4$-degree skin reaction in the $\mathrm{P}$ group and TPF group was $15.7 \%$ and $29.9 \%(\mathrm{P}=0.030)$, respectively. The rate of liver function injury in the $\mathrm{P}$ group was significantly lower than that in TPF group $(\mathrm{P}<0.05)$.

Conclusions: Compared with concurrent cisplatin chemotherapy and radiotherapy, the concurrent TPF regimen and IMRT showed no significant improvement in OS and PFS in patients with advanced NPC, but exhibited more severe hematologic toxicity, oral mucosal responses, skin reactions, and liver functional impairment.
\end{abstract}

Keywords: TPF regimen; intensity modulated radiotherapy (IMRT); locally advanced nasopharyngeal carcinoma (NPC); cisplatin; adverse effect

Submitted Jul 02, 2021. Accepted for publication Sep 03, 2021.

doi: 10.21037/apm-21-2073

View this article at: https://dx.doi.org/10.21037/apm-21-2073

\section{Introduction}

Nasopharyngeal carcinoma (NPC) is a group of malignant epithelial tumors with different etiopathogeneses and a broad range of histopathological appearances (1). The occurrence of the tumor is regional. It is uncommon in the United States, with only $0.2-0.5 / 10,000$ (2); however, in South part of China, the incidence is approximately 80 cases per 100,000, which poses a great threat to the local people (3).

Radiotherapy is an effective method for the treatment of early stage NPC. However, for local advanced NPC, the 5 -year survival rate after radiotherapy is only approximately $50 \%$ due to high local recurrence and distant metastasis rates. In recent years, increasing studies have shown that concurrent radiochemotherapy is superior to radiotherapy 
(4-8), and combined radiotherapy and chemotherapy has become the standard treatment for advanced NPC. To improve the therapeutic effects, the combination of neoadjuvant chemotherapy and concurrent chemo-radiation (CCRT) became an important research concern. Several clinical trials have demonstrated that docetaxel, cisplatin, and fluorouracil (TPF) regimen treatment significantly improves treatment outcomes compared with cisplatin plus 5-FU (PF) chemotherapy regimen $(9,10)$; however, the single $\mathrm{P}$ regimen is the most commonly used. Most concurrent radiochemotherapy studies have yielded encouraging results, showing that the locoregional control exceeded $90 \%$; however, the key problem to date has been distant failure. There were few studies to evaluate the effect of combined TPF and intensity modulated radiotherapy after TPF induction chemotherapy on locally advanced nasopharyngeal carcinoma. Whether the TPF regime followed by intensity modulated radiotherapy (IMRT) can reduce the distant metastasis of locally advanced NPC and improve the survival rate is still unclear. In this study, a retrospective analysis was conducted to evaluate the efficacy and toxicity of TPF regimen followed by IMRT on locally advanced NPC.

We present the following article in accordance with the STROBE reporting checklist (available at https://dx.doi. org/10.21037/apm-21-2073).

\section{Methods}

\section{Patient characteristics}

All procedures involving human participants were in compliance with the Declaration of Helsinki (as revised in 2013). The study was approved by the ethics committee of our hospital (No.: KY2021PJ125). And there is no informed consent because this is a retrospective study. Patients $(n=150)$ with locally advanced NPC who were treated at our hospital from August 2010 to December 2014 were retrospectively recruited to this study. The age of participants was from 19-76 years. The diagnosis and staging refer to WHO Type II/III Nasopharyngeal Carcinoma Pathology, and AJCC 7th edition [2009] staging standard III/IV (AB). The inclusion criteria included no distant metastasis, Eastern Cooperative Oncology Group (ECOG) scores of $0-1$, normal liver and kidney functions, and no serious cardiopulmonary or other chronic diseases. There were no significant differences between the 2 groups in age, gender, Karnofsky performance scale (KPS) scores, pathological type, T staging, $\mathrm{N}$ staging, and total staging (Table 1).

\section{Treatment details}

\section{Chemotherapy}

All participants were treated with a TPF regimen $\left(60 \mathrm{mg} / \mathrm{m}^{2}\right.$ docetaxel, day $1 ; 25 \mathrm{mg} / \mathrm{m}^{2}$ cisplatin, days $1-3$; and $500 \mathrm{mg} / \mathrm{m}^{2} 5 \mathrm{Fu} /$ fluorouracil, days $1-3$ ) for $2-3$ induction chemotherapy cycles. A total of 67 participants subsequently received concurrent TPF regime $\left(60 \mathrm{mg} / \mathrm{m}^{2}\right.$ docetaxel, day $1 ; 25 \mathrm{mg} / \mathrm{m}^{2}$ cisplatin, days $1-3$; and $500 \mathrm{mg} / \mathrm{m}^{2} 5 \mathrm{Fu}$, days $1-3$ ) and radiotherapy. The first cycle of chemotherapy was initiated on the first day of radiotherapy. The remaining 83 participants received $\mathrm{P}$ single-agent concurrent chemotherapy (25-40 mg/m² qw) during radiotherapy.

\section{Radiotherapy}

All participants underwent IMRT. The gross target volume (GTV) comprised the gross primary tumor (GTVnx) and involved lymph nodes (GTVnd) as defined by magnetic resonance imaging (MRI) or computed tomography (CT). The CTV1 comprised PGTVnx and PGTVnd and the high-risk subclinical area, including the entire nasopharynx, $1 / 3$ or $2 / 3$ of the slope (when the slope was violated, the entire slope was included), the wing, pterygopalatine fossa, part of the sphenoid sinus (for T3/T4 the entire sphenoid sinus was included), the posterior $1 / 4-1 / 3$ of the nasal cavity, the maxillary sinus and other high-risk areas, and the upper cervical lymph node region (posterior pharyngeal lymph nodes and II, III, VA lymph nodes). The CTV2 was a low-risk area, including the lower cervical lymph nodes (IV, VB region without lymph node metastasis). In the TPF group, PGTVnx participants were administered a radiation dose of 69.96-79.2 Gy/30-35 f, with a per fraction dose of 1.82.28 Gy and an average dose of $71 \mathrm{~Gy}$, for 6-7 weeks. The dosage of PGTVnx in the P group was 69.96-73.92 Gy/ $30-33 \mathrm{f}$, with a per fraction dose of 1.8-2.25 Gy and an average dosage of $70.48 \mathrm{~Gy}$, for 6-6.6 weeks. There was no statistically significant difference between the 2 groups $(\mathrm{P}=0.92)$. In the PGTVnd, PTV1, and PTV2 groups, the prescription doses were $66 \mathrm{~Gy}, 60 \mathrm{~Gy}$, and $54 \mathrm{~Gy}$. In the PGTVnx group, shrinking field radiotherapy or accelerated radiation therapy were used.

\section{Dose adjustment}

At the beginning of radiotherapy, the blood routine was assessed to ensure that the neutrophil count was $>1,500 / \mu \mathrm{L}$ 
Table 1 Patient and disease characteristics

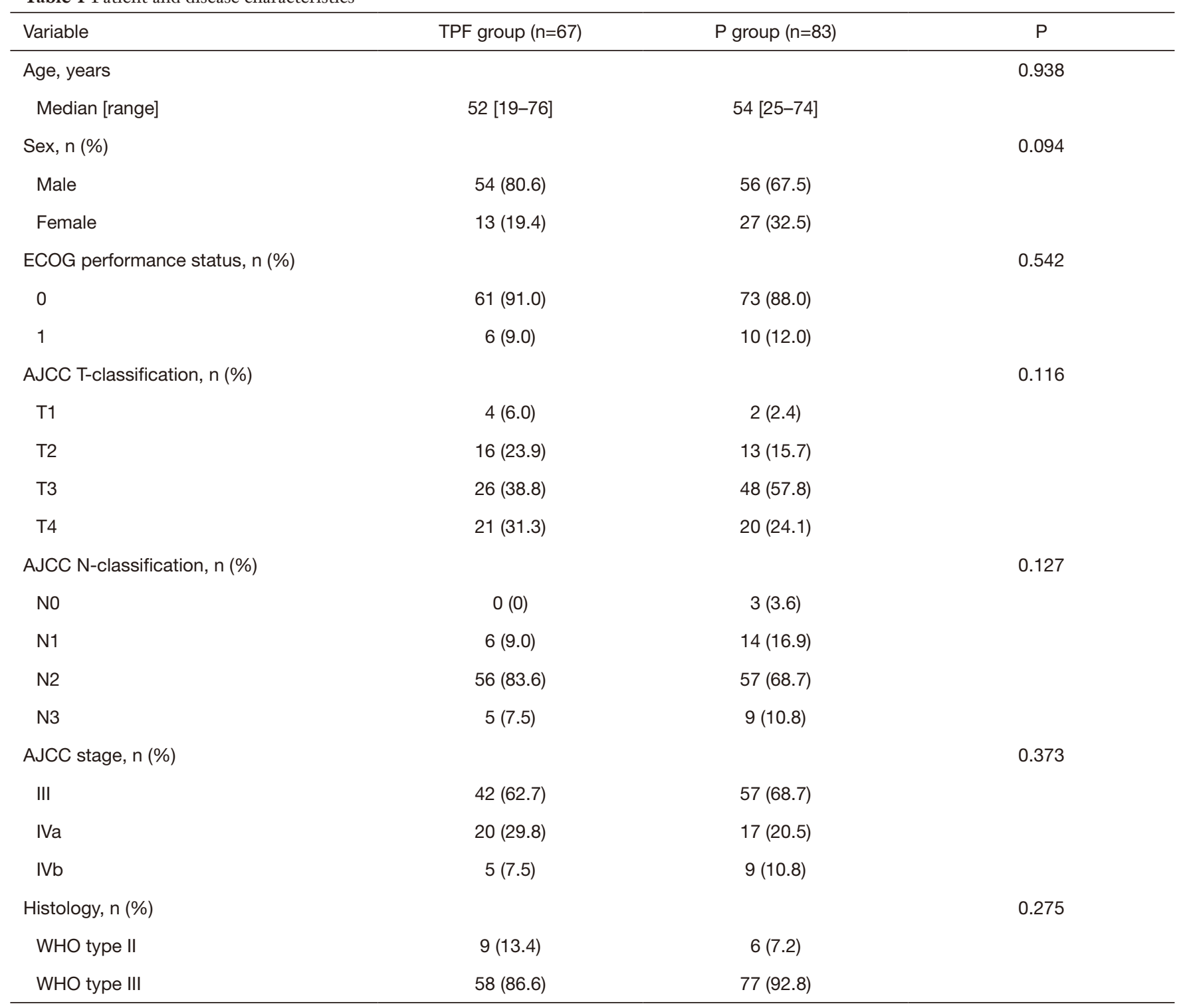

AJCC, American Joint Committee on Cancer; WHO, World Health Organization.

and the platelets count was $>1,000 / \mu \mathrm{L}$. During concurrent radiochemotherapy, the blood was examined once a week. When the neutrophil count was $<1,500 / \mu \mathrm{L}$ or the platelet count was $<1,000 / \mu \mathrm{L}$, chemotherapy was delayed $1-2$ weeks until the blood cell counts recovered. When the neutrophil minimum was $<1,000 / \mu \mathrm{L}$ or the platelet minimum was $<500 / \mu \mathrm{L}$, the chemotherapy dose was reduced by $20 \%$. When 4-degree hematologic toxicity or neutropenic fever occurs after the previous cycle of chemotherapy, the next cycle of chemotherapy should be suspended.

The efficacy and toxicity were evaluated according to
WHO classification criteria (11).

\section{Follow-up and evaluation}

Assessment of short-term efficacy based on physical examinations and MRI of the head and neck at 3 months after chemoradiotherapy. According to the Response Evaluation Criteria in Solid Tumors (RECIST), short-term outcomes were divided into progressive disease (PD), stable disease (SD), partial remission (PR), complete remission (CR). Adverse events were evaluated according to the 
Table 2 Treatment delivery

\begin{tabular}{|c|c|c|c|c|}
\hline Treatment & \multicolumn{2}{|c|}{ TPF group (N=67) } & \multicolumn{2}{|c|}{$P$ group $(\mathrm{N}=83)$} \\
\hline \multirow[t]{3}{*}{ Concurrent chemotherapy } & 1 & $9(13.4)$ & $1-2$ & $3(3.6)$ \\
\hline & 2 & $58(86.6)$ & $3-4$ & $19(22.9)$ \\
\hline & 3 & $0(0)$ & $5-6$ & $61(73.5)$ \\
\hline No delay & & $63(94.0)$ & & $81(97.6)$ \\
\hline Delayed less, than 1 week & & $2(3.0)$ & & $1(1.2)$ \\
\hline Delayed, 1-2 weeks & & $1(1.5)$ & & $1(1.2)$ \\
\hline Delayed more, than 2 weeks & & $1(1.5)$ & & $0(0)$ \\
\hline
\end{tabular}

latest version of the National Cancer Institute's Common Terminology Criteria for Adverse Events (NCI CTCAE $3.0)$. As the 2 participant groups were treated with $2-3$ cycles of TPF induction chemotherapy, we only evaluated the adverse events during chemoradiotherapy.

The participants were followed up for 4-66 months (median follow-up of 35 months). The first follow-up visit was $2-3$ months after chemoradiotherapy, and review was conducted once every 3 months in the first 2 years and at 4-6 months intervals until 5 years. The nasopharyngoscopy, nasopharyngeal MRI, head and neck CT, nasopharyngeal biopsy (when necessary), abdominal B-ultrasonography, and chest X-ray or chest CT were examined.

\section{Statistical analysis}

The software SPSS 20 (IBM Corp., Chicago, IL, USA) was used for statistical analysis. Kaplan-Meier method was used to calculate the overall survival (OS) and progressionfree survival (PFS). The chi-square test was used to analyze the count data and Student's $t$-test was used to analyze the measurement data. When $\mathrm{P}$ value $<0.05$, it was considered statistically significant.

\section{Results}

\section{Treatment program implementation}

In the TPF group, 58 participants $(86.6 \%)$ completed 2 cycles of chemotherapy during radiotherapy, and 40 of these individuals $(59.7 \%)$ started the second chemotherapy treatment within 21-28 days after the first cycle of chemotherapy.
Another 18 participants in the TPF group (26.9\%) started the second cycle of chemotherapy at 28-35 days after the first cycle of chemotherapy and had delayed chemotherapy. In the $\mathrm{P}$ group, 22 participants (26.5\%) completed treatment in fewer than 4 weeks, and 61 (73.5\%) completed 5 weeks or more of chemotherapy. According to a weekly $40 \mathrm{mg} / \mathrm{m}^{2}$ standard dosage of cisplatin, 61 participants completed treatment in 5 weeks and received a sufficient amount of concurrent chemotherapy. Interruption of radiotherapy occurred in 4 participants in the TPF group and 2 in the P group. Radiation dose reductions were not observed in any participants. The implementation of chemoradiotherapy for all 150 participants is listed in Table 2.

\section{Short-term treatment efficacy}

During the course of induction chemotherapy, no hematologic toxicity of grade III or above was observed. The short-term response at 3 months after the induction chemotherapy and CCRT in the 2 groups is listed in Table 3. The response rates of nasopharyngeal lesions and cervical lymph nodes in the 2 groups were $100 \%$ and $98.8 \%$, respectively $(\mathrm{P}=1.0)$. The $\mathrm{CR}$ and $\mathrm{PR}$ rates in the $\mathrm{TPF}$ group were $31.3 \%$ and $68.7 \%$, respectively, while the rates in the $\mathrm{P}$ group were 26.5 and $72.3 \%$, respectively. The effect of the 2 groups was not significantly different $(\mathrm{P}=0.555)$.

\section{Acute toxicity}

The incidence of hematologic toxicity (including neutropenia, thrombocytopenia, and anemia) in the first, second, third, and fourth stages in the TPF and P groups 
Table 3 Response to the induction of chemotherapy and chemoradiation therapy

\begin{tabular}{|c|c|c|c|c|c|}
\hline \multirow{2}{*}{ Response } & \multicolumn{2}{|c|}{ TPF group $(n=67)$} & \multicolumn{2}{|c|}{$P$ group $(n=83)$} & \multirow{2}{*}{$P$ value } \\
\hline & $\mathrm{n}$ & $\%$ & $\mathrm{n}$ & $\%$ & \\
\hline CR & 21 & 31.3 & 22 & 26.5 & 0.555 \\
\hline PR & 46 & 68.7 & 60 & 72.3 & \\
\hline SD & 0 & 0 & 1 & 1.2 & \\
\hline PD & 0 & 0 & 0 & 0 & \\
\hline ORR (CR+PR) & 67 & 100 & 82 & 98.8 & 1.0 \\
\hline
\end{tabular}

CR, complete response; PR, partial response; SD, stable disease; PD, progressive disease; ORR, overall response rate.

was $22.4 \%, 41.8 \%, 28.4 \%$, and $6.0 \%$, and $18.1 \%, 55.4 \%$, $13.3 \%$ and $3.6 \%$, respectively. Similarly, the rates of oral mucosal responses in grades $1,2,3$, and 4 were $4.5 \%$, $58.2 \%, 35.8 \%$, and $1.5 \%$ and $9.6 \%, 72.3 \%, 14.5 \%$, and $3.6 \%$ in the TPF and $\mathrm{P}$ groups, respectively $(\mathrm{P}=0.017)$. The skin reactions in grades $1,2,3$, and 4 during CCRT were $4.5 \%, 65.7 \%, 28.4 \%$, and $1.5 \%$ and $20.5 \%, 63.9 \%, 14.5 \%$, and $1.2 \%$ in the TPF and $\mathrm{P}$ groups, respectively $(\mathrm{P}=0.014)$. During chemoradiotherapy, the TPF group showed a higher incidence of grade 3-4 liver damage and grade 3-4 diarrhea, and there was no significant difference in renal function between the 2 groups. The acute toxicity of the TPF and $\mathrm{P}$ groups is shown in Table 4.

\section{Follow up}

Participants' median follow-up time was 35 months (4-66 months). The 2-, 3-, and 5-year rates of PFS were $86.6 \%, 80.2 \%$, and $77.2 \%$ and $82.7 \%, 74.2 \%$ and $71.3 \%$ in the TPF and $\mathrm{P}$ groups, respectively $(\mathrm{P}=0.396)$. The OS at 2,3 , and 5 years was $96.9 \%, 93.5 \%$, and $85.2 \%$ and $98.7 \%$, $93.1 \%$, and $78.4 \%$ in the $\mathrm{TPF}$ and $\mathrm{P}$ groups, respectively $(\mathrm{P}=0.369)$. There was no significant difference between the 2 groups in PFS and OS (Figures 1 and 2).

The main patterns of treatment failure for NPC were: (I) local recurrence (including nasopharyngeal lesion recurrence and regional lymph node recurrence), (II) distant metastasis (including liver, lung, and bone metastases), (III) local recurrence and distant metastasis, and (IV) second primary tumors. In the TPF group, 4 cases had local recurrence and 9 cases had distant metastases. In the $\mathrm{P}$ group, 10 participants had local recurrence, 7 had distant metastasis, 1 had both local recurrence and distant metastasis, and 2 had a second
Table 4 Acute toxicity of radiochemotherapy

\begin{tabular}{|c|c|c|c|c|c|}
\hline \multirow{2}{*}{ Acute toxicity } & \multicolumn{2}{|c|}{ TPF group $(n=67)$} & \multicolumn{2}{|c|}{$P$ group $(n=83)$} & \multirow{2}{*}{$P$ value } \\
\hline & $\mathrm{n}$ & $\%$ & $\mathrm{n}$ & $\%$ & \\
\hline Hematologic toxici & & & & & 0.043 \\
\hline Grade 1-2 & 43 & 64.2 & 61 & 73.5 & \\
\hline Grade 3-4 & 23 & 34.3 & 14 & 16.9 & \\
\hline Diarrhea & & & & & 0.036 \\
\hline Grade 1-2 & 9 & 13.4 & 3 & 3.6 & \\
\hline Grade 3-4 & 3 & 4.5 & 1 & 1.2 & \\
\hline Liver dysfunction & & & & & 0.015 \\
\hline Grade 1-2 & 9 & 13.4 & 6 & 7.2 & \\
\hline Grade 3-4 & 5 & 7.5 & 0 & 0 & \\
\hline $\begin{array}{l}\text { Kidney } \\
\text { dysfunction }\end{array}$ & & & & & 0.828 \\
\hline Grade 1-2 & 2 & 3.0 & 2 & 2.4 & \\
\hline Grade 3-4 & 0 & 0 & 0 & 0 & \\
\hline $\begin{array}{l}\text { Mucous } \\
\text { membrane }\end{array}$ & & & & & 0.017 \\
\hline Grade 1-2 & 42 & 62.7 & 68 & 81.9 & \\
\hline Grade 3-4 & 25 & 37.3 & 15 & 18.1 & \\
\hline Skin & & & & & 0.014 \\
\hline Grade 1-2 & 47 & 70.1 & 70 & 84.3 & \\
\hline Grade 3-4 & 20 & 29.9 & 13 & 15.7 & \\
\hline
\end{tabular}

primary tumors. There was no significant difference in failure pattern for the 2 groups. The patterns of treatment failure are listed in Table 5 .

\section{Discussion}

In China, NPC is one of the common malignant tumors, particularly in South China. Most cases of NPC are already locally advanced at the time of diagnosis. A prospective, randomized study confirmed that IMRT can provide improved local-recurrence free survival, especially in latestage NPC patients and is associated with a lower incidence of toxicities comparing with 2D-CRT group (12). IMRT group got 5 -year actuarial local control rate of $90.5 \%$ and 2D-CRT group was $84.7 \%$. The local control rates of T3/T4 stage were $91 \% / 81.5 \%$ in the IMRT group, and 


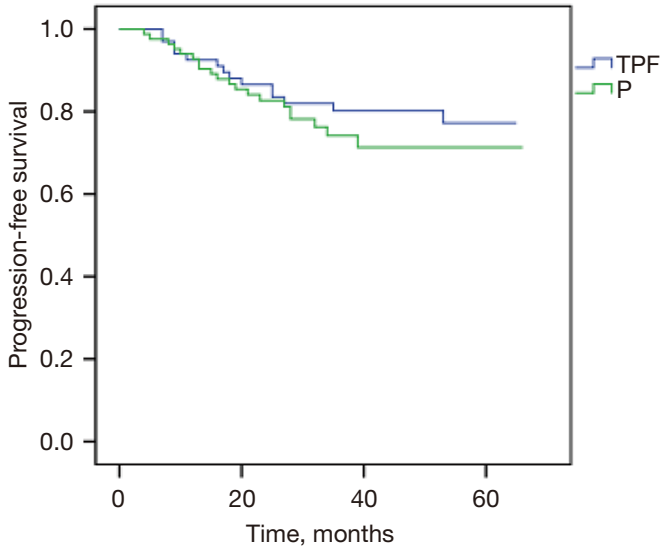

Figure 1 PFS of participants in TPF and P groups. The 5-year PFS rates were $77.2 \%$ and $71.3 \%$, respectively $(\mathrm{P}=0.396)$. PFS, progression-free survival.

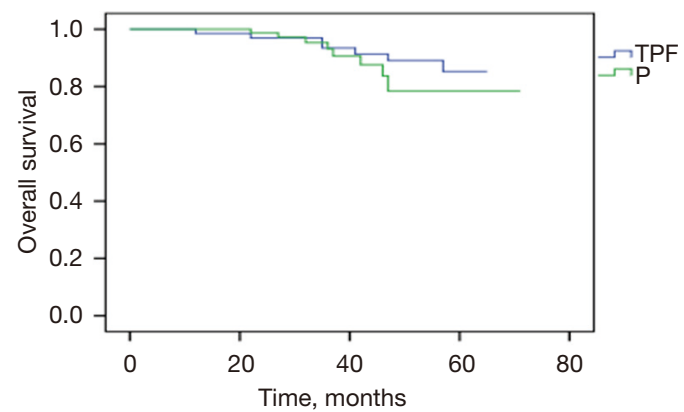

Figure 2 OS of participants in the TPF and $\mathrm{P}$ groups. The 5 -year OS rates were $85.2 \%$ and $78.4 \%$, respectively $(\mathrm{P}=0.369)$. OS, overall survival.

Table 5 Patterns of failure

\begin{tabular}{lccccccc}
\hline \multirow{2}{*}{ Failure patterns } & \multicolumn{2}{c}{ TPF group } & & \multicolumn{3}{c}{$\mathrm{P}$ group } & \\
\cline { 2 - 3 } & $\mathrm{n}$ & $\%$ & & $\mathrm{n}$ & $\%$ & P value \\
\hline Local & 4 & 6.0 & & 10 & 12.0 & 0.101 \\
Distance & 9 & 13.4 & 7 & 8.4 & 0.324 \\
Local and distance & 0 & 0 & 1 & 1.2 & 0.439 \\
Second primary malignancy & 0 & 0 & 2 & 2.4 & 0.201 \\
\hline
\end{tabular}

$80 \% / 62.2 \%$ in the $2 \mathrm{D}$-CRT group, respectively. When stratified by stage, only significant difference was noticed in stage III disease. Radiation-induced toxicities were significantly lower in patients in IMRT group than those in 2D-CRT group. Another study from LIAO published a similar result (13). In patients with severe skull-base invasion, IMRT group improved 4-year OS, DFS, LRRFS when compared with 2D-CRT (OS: 65.6\% vs. 81.8\%, $\mathrm{P}=0.000$; DFS: $57.3 \%$ vs. $73.3 \%, \mathrm{P}=0.000$; LRRFS: $76.5 \%$ vs. $87.5 \%, \mathrm{P}=0.003)$. Radiation therapy techniques were considered an independent prognostic factor for OS $(\mathrm{HR}=0.457, \mathrm{P}=0.000)$, DFS (HR $=0.547, \mathrm{P}=0.000)$ and LRRFS ( $\mathrm{HR}=0.503, \mathrm{P}=0.004$ ) especially in patients with severe invasion. IMRT was associated with better outcome. The survival rate of patients with locally advanced NPC is not satisfactory; particularly, the 5-year OS has been shown at only approximately $35 \%$ for patients with cancers at stages IVA-B (14). Currently, induction chemotherapy combined with concurrent chemoradiotherapy has achieved good therapeutic effects for patients with locally advanced NPC $(15,16)$. The PF regimen is the most commonly used induction chemotherapy. In the last few years, docetaxel combined with a cisplatin-based regimen has also been applied as induction chemotherapy.

Subsequently, CCRT has achieved better outcomes and the toxicity could be tolerated (17). Lorch et al. proposed that treatment for locally advanced head and neck squamous cell carcinoma using TPF was superior to PF in terms of local control rate, OS, and PFS (18). Hui et al. conducted a phase II trial and concluded that there was a significant difference between TPF induction chemotherapy and concurrent chemoradiation and chemotherapy alone, revealing 3 -year OS rates of $94.1 \%$ and $67.7 \%$, respectively $(\mathrm{P}=0.012)$ (19). Kong et al. proposed that TPF induction chemotherapy has high short-term efficiency and is well tolerated, which is worthy of further study (20). Zeng et al. published a retrospective analysis showed 3-year OS rates of $87.9 \%$ and $87.4 \%$ for TPF induction chemotherapy group and GP induction chemotherapy group, no statistically significant $(\mathrm{P}=0.928)(21)$. Considering only the survival, TPF becomes the best choice for locally advanced nasopharyngeal. However patients got TPF induction chemotherapy may suffer more serious adverse event, especially hematological toxicity greater than or equal to grade 3 and oral mucositis (22). There is no phase III clinical trial to verify which induction chemotherapy program is better. Thus, in the present study, we selected TPF as the induction chemotherapy for NPC.

The main failure pattern of local advanced NPC is local failure and distant metastasis (23). Studies have shown that IMRT combined with synchronous chemotherapy increases the local control rate of NPC by up to $90 \%$ or more (24). The NPC-9901 (4) and NPC 9902 (8) trials have suggested that concurrent chemotherapy during radiotherapy may 
further increase local control and OS, and also improve the distant metastasis control rate in NPC.

Single-agent chemotherapy primarily increased radiotherapy sensitivity. The decreased concentration of chemotherapeutic drugs per week reduced the inhibitory effect on distant metastasis. It remains unknown whether chemotherapy could be performed during radiotherapy using a 3-drug combination regimen to reduce the chance of distant metastasis, thereby improving the survival rate. In this study, we attempted to solve this problem through a retrospective analysis of 150 cases of locally advanced NPC. All participants received 2-3 cycles of TPF induction chemotherapy. Subsequently, 66 participants were administered 3 TPF drugs combined with CCRT, and 84 participants were administered with single cisplatin chemotherapy combined with CCRT. The efficiency and toxicity were observed in the 2 groups. The results showed that there were no significant differences in the efficiency of the 2 groups, but the hematologic toxicity and mucosal and skin toxicity were significantly different. In the TPF group, hematologic toxicity, oral mucosal reaction, skin reactions, and liver damage were significantly higher than in the single drug $\mathrm{P}$ group. Considering the late $\mathrm{T}$ stage or lymph node metastasis in patients, we also conducted a relatively detailed stratification. The results showed that N3 patients (IV or $\mathrm{V}$ regional lymph node metastasis) were more prone to distant metastasis. Comparing the $\mathrm{T} 4$ or $\mathrm{N} 3$ patients in the 2 groups, we found that the PFS and OS were not significantly different. Thus, the results of this retrospective analysis showed that TPF induction chemotherapy, followed by TPF with 3 drugs in combination with radiotherapy showed no advantageous effect compared with $\mathrm{P}$ singledrug concurrent radiotherapy, but generated more serious toxicity. Thus, this treatment should not be recommended as a general therapy.

However, the best treatment for NPC has not yet been determined, and the advantage of induction chemotherapy and adjuvant chemotherapy treatment is uncertain. If locally advanced NPC patients have not received induction chemotherapy, then radiotherapy during 3- or 2-drug combination chemotherapy is more effective than singleagent chemotherapy, and this idea is worthy of further exploration. Chemotherapeutics, such as 5-fluorouracil, platinum analogs, and DNA topoisomerase I-targeting drugs, are commonly used when combined with radiotherapy and can achieve better local-regional therapeutic effects. Molecular targeted agents that target DNA or not are also helpful to radiation therapy, such as EGFR blockers and
COX-2 inhibitors $(25,26)$. There are several biomarkers, such as NFBD-1, GP96/GDF-15, LMP-1, Bcl-2 etc., classified according to the main mechanisms of radiosensitization, to enhance the responsiveness of NPC cells to radiation treatment $(27,28)$. Targeting the biomarkers to enhance the radiosensitivity of NPC is very promising and practicable. All the chemical and biological methods that can affect the sensitivity to radiation are named radiosensitizers and we hope large cohort clinical trials will verify the feasibility, availability and safety of these radiosensitizers to enhance the radiosensitivity.

Anyway inherent biases do exist in the retrospective study, large sample size and, in particular, prospective trials in randomization may precisely validate the effects of TPF on the survival of NPC patients.

In conclusion, for patients with locally advanced NPC, the combination of TPF and radiotherapy after TPF induction chemotherapy did not benefit the PFS and OS, but increased the hematological toxicity, hepatotoxicity, and skin and mucous membrane reactions, compared to the combination of single cisplatin with radiotherapy. Therefore, the clinical application of the TPF regimen should be carefully considered.

\section{Acknowledgments}

Funding: None.

\section{Footnote}

Reporting Checklist: The authors have completed the STROBE reporting checklist. Available at https://dx.doi. org/10.21037/apm-21-2073

Data Sharing Statement: Available at https://dx.doi. org/10.21037/apm-21-2073

Conflicts of Interest: All authors have completed the ICMJE uniform disclosure form (available at https://dx.doi. org/10.21037/apm-21-2073). The authors have no conflicts of interest to declare.

Ethical Statement: The authors are accountable for all aspects of the work in ensuring that questions related to the accuracy or integrity of any part of the work are appropriately investigated and resolved. All procedures performed in this study involving human participants were in accordance with the Declaration of Helsinki (as revised in 
2013). The study was approved by the ethics committee of our hospital (No.: KY2021PJ125). And there is no informed consent because this is a retrospective study.

Open Access Statement: This is an Open Access article distributed in accordance with the Creative Commons Attribution-NonCommercial-NoDerivs 4.0 International License (CC BY-NC-ND 4.0), which permits the noncommercial replication and distribution of the article with the strict proviso that no changes or edits are made and the original work is properly cited (including links to both the formal publication through the relevant DOI and the license). See: https://creativecommons.org/licenses/by-nc-nd/4.0/.

\section{References}

1. Petersson F. Nasopharyngeal carcinoma: a review. Semin Diagn Pathol 2015;32:54-73.

2. Kamran SC, Riaz N, Lee N. Nasopharyngeal carcinoma. Surg Oncol Clin N Am 2015;24:547-61.

3. Al-Sarraf M, LeBlanc M, Giri PG, et al. Chemoradiotherapy versus radiotherapy in patients with advanced nasopharyngeal cancer: phase III randomized Intergroup study 0099. J Clin Oncol 1998;16:1310-7.

4. Lin JC, Jan JS, Hsu CY, et al. Phase III study of concurrent chemoradiotherapy versus radiotherapy alone for advanced nasopharyngeal carcinoma: positive effect on overall and progression-free survival. J Clin Oncol 2003;21:631-7.

5. Chan AT, Leung SF, Ngan RK, et al. Overall survival after concurrent cisplatin-radiotherapy compared with radiotherapy alone in locoregionally advanced nasopharyngeal carcinoma. J Natl Cancer Inst 2005;97:536-9.

6. Zhang L, Zhao C, Peng PJ, et al. Phase III study comparing standard radiotherapy with or without weekly oxaliplatin in treatment of locoregionally advanced nasopharyngeal carcinoma: preliminary results. J Clin Oncol 2005;23:8461-8.

7. He Y, Guo T, Wang J, et al. Which induction chemotherapy regimen followed by cisplatin-based concurrent chemoradiotherapy is the best choice among PF, TP and TPF for locoregionally advanced nasopharyngeal carcinoma? Ann Transl Med 2019;7:104.

8. Wee J, Tan EH, Tai BC, et al. Randomized trial of radiotherapy versus concurrent chemoradiotherapy followed by adjuvant chemotherapy in patients with American Joint Committee on Cancer/International
Union against cancer stage III and IV nasopharyngeal cancer of the endemic variety. J Clin Oncol 2005;23:6730-8.

9. Hitt R, López-Pousa A, Martínez-Trufero J, et al. Phase III study comparing cisplatin plus fluorouracil to paclitaxel, cisplatin, and fluorouracil induction chemotherapy followed by chemoradiotherapy in locally advanced head and neck cancer. J Clin Oncol 2005;23:8636-45.

10. Posner MR, Hershock DM, Blajman CR, et al. Cisplatin and fluorouracil alone or with docetaxel in head and neck cancer. N Engl J Med 2007;357:1705-15.

11. Miller AB, Hoogstraten B, Staquet M, et al. Reporting results of cancer treatment. Cancer 1981;47:207-14.

12. Peng G, Wang T, Yang KY, et al. A prospective, randomized study comparing outcomes and toxicities of intensity-modulated radiotherapy vs. conventional two-dimensional radiotherapy for the treatment of nasopharyngeal carcinoma. Radiother Oncol 2012;104:286-93.

13. Liao S, Xie Y, Feng Y, et al. Superiority of intensitymodulated radiation therapy in nasopharyngeal carcinoma with skull-base invasion. J Cancer Res Clin Oncol 2020;146:429-39.

14. Heng DM, Wee J, Fong KW, et al. Prognostic factors in 677 patients in Singapore with nondisseminated nasopharyngeal carcinoma. Cancer 1999;86:1912-20.

15. Airoldi M, Gabriele AM, Garzaro M, et al. Induction chemotherapy with cisplatin and epirubicin followed by radiotherapy and concurrent cisplatin in locally advanced nasopharyngeal carcinoma observed in a non-endemic population. Radiother Oncol 2009;92:105-10.

16. Komatsu M, Tsukuda M, Matsuda H, et al. Comparison of concurrent chemoradiotherapy versus induction chemotherapy followed by radiation in patients with nasopharyngeal carcinoma. Anticancer Res 2012;32:681-6.

17. Ekenel M, Keskin S, Basaran M, et al. Induction chemotherapy with docetaxel and cisplatin is highly effective for locally advanced nasopharyngeal carcinoma. Oral Oncol 2011;47:660-4.

18. Lorch JH, Goloubeva O, Haddad RI, et al. Induction chemotherapy with cisplatin and fluorouracil alone or in combination with docetaxel in locally advanced squamouscell cancer of the head and neck: long-term results of the TAX 324 randomised phase 3 trial. Lancet Oncol 2011;12:153-9.

19. Hui EP, Ma BB, Leung SF, et al. Randomized phase II trial of concurrent cisplatin-radiotherapy with or without neoadjuvant docetaxel and cisplatin in advanced 
nasopharyngeal carcinoma. J Clin Oncol 2009;27:242-9.

20. Kong L, Zhang YW, Hu CS, et al. Neoadjuvant chemotherapy followed by concurrent chemoradiation for locally advanced nasopharyngeal carcinoma. Chin J Cancer 2010;29:551-5.

21. Zeng Z, Yan RN, Tu L, et al. Assessment of Concurrent Chemoradiotherapy plus Induction Chemotherapy in Advanced Nasopharyngeal Carcinoma: Cisplatin, Fluorouracil, and Docetaxel versus Gemcitabine and Cisplatin. Sci Rep 2018;8:15581.

22. He Y, Guo T, Wang J, et al. Which induction chemotherapy regimen followed by cisplatin-based concurrent chemoradiotherapy is the best choice among PF, TP and TPF for locoregionally advanced nasopharyngeal carcinoma? Ann Transl Med 2019;7:104.

23. Lee AW, Sze WM, Au JS, et al. Treatment results for nasopharyngeal carcinoma in the modern era: the Hong Kong experience. Int J Radiat Oncol Biol Phys 2005;61:1107-16.

Cite this article as: Zheng $\mathrm{L}$, Xu Q, Yang Z, Bei Y, Tong J, Ye S, $\mathrm{Hu} J$, Chen X, Lv J. The effect of combined TPF and intensity modulated radiotherapy after TPF induction chemotherapy on locally advanced nasopharyngeal carcinoma: a retrospective analysis. Ann Palliat Med 2021;10(9):9669-9677. doi: 10.21037/ apm-21-2073
24. Lee N, Harris J, Garden AS, et al. Intensity-modulated radiation therapy with or without chemotherapy for nasopharyngeal carcinoma: radiation therapy oncology group phase II trial 0225. J Clin Oncol 2009;27:3684-90.

25. Spalding AC, Lawrence TS. New and emerging radiosensitizers and radioprotectors. Cancer Invest 2006;24:444-56.

26. Kvols LK. Radiation sensitizers: a selective review of molecules targeting DNA and non-DNA targets. J Nucl Med 2005;46 Suppl 1:187S-90S.

27. Rong D, Lin X, Luo Y, et al. Identification of the differentially expressed proteins in nasopharyngeal carcinoma by proteomics. Transl Cancer Res 2020;9:21-9.

28. Chen W, Hu GH. Biomarkers for enhancing the radiosensitivity of nasopharyngeal carcinoma. Cancer Biol Med 2015;12:23-32.

(English Language Editor: J. Jones) 